\title{
OD Características agronômicas do girassol irrigado com águas salinas em substratos com fertilizantes orgânicos
}

Geocleber Gomes de Sousa ${ }^{1}$

Thales Vinícius de Araújo Viana²

Mário de Oliveira Rebouças Neto ${ }^{3}$

Giovana Lopes da Silva, ${ }^{4}$

Benito Moreira de Azevedo 5

Fellype Rodrigo Barroso Costa ${ }^{6}$

\section{Resumo}

As plantas respondem diferenciadamente aos efeitos dos sais nas distintas fases do seu ciclo. No entanto, o uso de condicionantes orgânicos pode atenuar o efeito do estresse salino sobre o crescimento das plantas. Este trabalho teve como objetivo avaliar o efeito do estresse salino no crescimento inicial de plantas de girassol cultivadas em substratos com diferentes fertilizantes orgânicos. 0 trabalho foi conduzido na área experimental da Estação Agrometeorológica da Universidade Federal do Ceará, em Fortaleza, no período de setembro a novembro de 2013. O delineamento experimental empregado foi inteiramente casualizado, em um esquema fatorial $4 \times 2$, referente aos substratos $\left(\mathrm{S}_{1}=\right.$ areia + arisco + composto orgânico; $\mathrm{S}_{2}=$ areia + arisco + biofertilizante de caranguejo; $\mathrm{S}_{3}=$ areia + arisco + biofertilizante bovino de fermentação aeróbia; $S_{4}=$ areia + arisco + biofertilizante bovino de fermentação anaeróbia), com duas condutividades elétricas da água de irrigação (0,8 e 5,0 dS m-1), com 5 repetições. Foram analisadas as seguintes variáveis: número de folhas, diâmetro do caule, área foliar e altura de plantas, matéria seca da parte aérea, da raiz e total. O S3 e o S4 proporcionam maior altura de planta e área foliar nas plantas irrigadas com água de baixa salinidade. As plantas cultivadas com o S3 e S4 apresentaram maiores valores em número de folhas, diâmetro do caule, matéria seca da parte aérea, da raiz e total.

Palavras-chave: Helianthusannuus L. Estresse salino. Condicionantes orgânicos.

\section{Introdução}

O girassol (Helianthusannuus L.) é uma dicotiledônea anual originária da América do Norte (ZOBIOLE et al., 2010) que pertence à família Asteraceae, sendo uma cultura que se destaca pela elevada produtividade de óleo, por isso, possui grande potencial para a produção de biocombustíveis (UNGARO, 2006), além da capacidade de adaptar-se a diferentes condições ambientais. Tais características proporcionam sua introdução nas diferentes condições edafoclimáticas das áreas tra-

\footnotetext{
1 Universidade da Integração Internacional da Lusofonia Afro-Brasileira, professor, Redenção, Ceará, Brasil. sousasolosgeo@hotmail.com 2 Universidade Federal do Ceará, professor, Fortaleza, Ceará, Brasil. thales@ufc.br 3 Instituto Federal do Piauí, professor, Campo Maior, Piauí, Brasil. agromario@gmail.com 4 Faculdades Nordeste, professora, Fortaleza, Ceará, Brasil. gsilva13@fanor.edu.br 5 Universidade Federal do Ceará, professor, Fortaleza, Ceará, Brasil. benitoazevedo@hotmail.com 6 Universitat Politécnica de Valencia, Doutorando, Valência, Espanha. fellyperodrigo@yahoo.com.br
} 
dicionais de produção (EMPRESA BRASILEIRA DE PESQUISA AGROPECUÁRIA - EMBRAPA, 1997), possibilitando seu cultivo em todas as regiões do Brasil (CASTRO; FARIAS, 2005).

Cabe ressaltar que a forma como essa cultura comporta-se depende de diversos fatores como a escolha da época de semeadura, do genótipo escolhido, do correto manejo da fertilidade do solo, além de fatores ambientais como a distribuição de água ao longo do desenvolvimento da cultura (LEITE, 2007). Além disso, a qualidade da água de irrigação constitui-se em fator relevante no desenvolvimento das plantas.

A salinidade reduz a capacidade fotossintética das plantas, por conta de limitações estomáticas e não estomáticas, o que causa redução no crescimento e na produtividade de algumas culturas (SILVA et al. , 2013; GOMES et al., 2011). A intensidade desses efeitos depende ainda de outros fatores, como espécie, cultivar, estádio fenológico da cultura, tipos dos sais, intensidade e duração do estresse salino, manejo cultural e qualidade da água de irrigação (SANTANA et al., 2007; NEVES et al., 2009).

Uma das alternativas para minimizar os efeitos danosos dos sais durante o crescimento das plantas é o emprego de fontes orgânicas de origem animal, como, por exemplo, o biofertilizante bovino de fermentação anaeróbia (SILVA et al., 2011) e aeróbia (COSTA et al., 2014) e de caranguejo de fermentação aeróbia (SOUSA et al., 2014). Esses autores relatam ainda que, mesmo sob estresse salino, o uso desses insumos orgânicos proporciona melhores resultados de altura de plantas, diâmetro do caule e área foliar em plantas de feijão-de-corda e de matéria seca da parte aérea em plantas de amendoim cultivadas em vasos.

Os biofertilizantes são adubos orgânicos líquidos produzidos em meio aeróbico ou anaeróbico a partir de uma mistura de material orgânico (esterco fresco) e água (PENTEADO, 2007). Possuem em suas composições nutrientes necessários ao desenvolvimento das culturas, reduzem a utilização de produtos químicos gerando economia de insumos e podem melhorar os atributos físicos e biológicos do solo.

A partir do exposto, o presente trabalho teve como objetivo avaliar o efeito do estresse salino no crescimento inicial de plantas de girassol cultivadas em substratos com diferentes fertilizantes orgânicos.

\section{Material e métodos}

O trabalho foi conduzido em uma área experimental da Estação Agrometeorológica da UFC, em Fortaleza, Ceará, (345'S; 38³3'W e altitude de $19 \mathrm{~m}$ ), no período de setembro a novembro de 2013. De acordo com a classificação de Köppen (1918), a área do experimento está localizada em uma região de clima Aw', caracterizado como tropical chuvoso, muito quente, com chuvas predominantes nas estações do verão e do outono. Os dados meteorológicos verificados durante o experimento podem ser observados na Tabela 1.

Tabela 1. Valores médios mensais da temperatura, umidade relativa (UR \%), velocidade do vento (VV) e valores da precipitação mensal durante o experimento

\begin{tabular}{|c|c|c|c|c|c|c|}
\hline & \multicolumn{3}{|c|}{ Temperatura $\left({ }^{\circ} \mathrm{C}\right)$} & \multirow{2}{*}{$\begin{array}{l}\text { UR } \\
(\%)\end{array}$} & \multirow{2}{*}{$\begin{array}{l}\text { VV } \\
\left(\mathrm{ms}^{-1}\right)\end{array}$} & \multirow{2}{*}{$\begin{array}{c}\text { Precipitação } \\
(\mathrm{mm})\end{array}$} \\
\hline & Máxima & Mínima & Média & & & \\
\hline Setembro & 31,1 & 23,4 & 27,3 & 70 & 4,4 & 16,7 \\
\hline Outubro & 31,2 & 23,6 & 27,4 & 68 & 4,3 & 5,7 \\
\hline Novembro & 31,2 & 24,0 & 27,6 & 75 & 4,5 & 10,1 \\
\hline
\end{tabular}

Fonte: Estação Agrometeorológica da Universidade Federal do Ceará 
O delineamento experimental utilizado foi o inteiramente casualizado, em arranjo fatorial $4 \times 2$, com cinco repetições. Os tratamentos foram constituídos de quatro fertilizantes orgânicos aplicados no substrato de uma vez $\left(\mathrm{S}_{1}=\right.$ areia + arisco + composto orgânico; $\mathrm{S}_{2}=$ areia + arisco + biofertilizante de caranguejo; $\mathrm{S}_{3}=$ areia + arisco + biofertilizante bovino de fermentação aeróbia; $\mathrm{S}_{4}=$ areia + arisco + biofertilizante bovino de fermentação anaeróbia), com duas condutividades elétricas da água de irrigação (1,0 dS m $\mathrm{m}^{-1}$ e 5,0 dS $\left.\mathrm{m}^{-1}\right)$ aplicadas aos vasos.

O biofertilizante foi diluído em água na razão de 1:1, aplicado de uma única vez, em volume equivalente a $10 \%$ (1,0 $\left.\mathrm{L}_{\text {planta-1 }}{ }^{-1}\right)$ do volume do substrato. Foram utilizadas sementes de girassol Embrapa 122, as quais foram plantadas em vasos plásticos com capacidade de 10 litros. Após 0 estabelecimento das plântulas, aos 8 dias após a semeadura (DAS), fez-se o desbaste deixando-se uma planta por vaso.

A partir de uma mistura de esterco bovino e água na proporção 1:1 com base em volume, foi preparado o biofertilizante bovino de fermentação aeróbia. Nesse sistema a mistura (esterco bovino e água) foi armazenada em uma caixa d'água com capacidade para 1.000 litros e permaneceu por um período de 30 dias sofrendo fermentação aeróbia. Semanalmente era realizada a homogeneização desse sistema (SANTOS et al., 2014).

O biofertilizante bovino de fermentação anaeróbia foi preparado a partir de uma mistura de partes iguais de esterco fresco bovino e água não salina ( $C E=0,8 \mathrm{dS} \mathrm{m}^{-1}$ ), sob fermentação anaeróbia, durante 30 dias, em recipiente plástico. Para se obter o sistema anaeróbio, a mistura foi colocada em uma bombona plástica de $240 \mathrm{~L}$, deixando-se um espaço vazio de 15 a $20 \mathrm{~cm}$ no seu interior e fechada hermeticamente. Na tampa foi adaptada uma mangueira com a outra extremidade merguIhada em um recipiente com água na altura de $20 \mathrm{~cm}$, para a saída de gases (PENTEADO, 2007).

Por outro lado, o biofertilizante de caranguejo enriquecido com fermentação anaeróbia foi preparado a partir de uma mistura de $60 \mathrm{~kg}$ de restos de caranguejo (pata e cabeça) moído, $5 \mathrm{~kg}$ de rapadura preta moída, 2,0 L de leite e $100 \mathrm{~L}$ de água não salina (CEa $=0,8 \mathrm{dS} \mathrm{m}-1$ ) em um reservatório de $300 \mathrm{~L}$, deixando-se fermentar por um período de 90 dias (SOUSA et al., 2014).

Foram coletadas amostras dos substratos e encaminhadas ao laboratório para análise da fertilidade. Os valores da análise podem ser observados na Tabela 2.

Tabela 2. Análise da fertilidade dos substratos utilizados

\begin{tabular}{|c|c|c|c|c|c|c|c|c|c|c|c|}
\hline \multirow{3}{*}{ Substratos } & \multicolumn{11}{|c|}{ Atributos químicos do solo } \\
\hline & \multicolumn{2}{|c|}{$\left(\mathrm{g} \mathrm{kg}^{-1}\right)$} & \multirow[b]{2}{*}{$\mathrm{pH}$} & \multirow{2}{*}{$\frac{\left(\mathrm{mg} \mathrm{dm}^{-3}\right)}{P}$} & \multicolumn{5}{|c|}{$\left(\mathrm{mmol}_{\mathrm{c}} \mathrm{dm}^{-3}\right)$} & \multirow{2}{*}{$\begin{array}{l}\text { (\%) } \\
\text { PST }\end{array}$} & \multirow{2}{*}{$\begin{array}{c}(\mathrm{dS} \\
\left.\mathrm{m}^{-1}\right) \\
\mathrm{Ce}\end{array}$} \\
\hline & C & MO & & & K & $\mathrm{Ca}$ & Mg & $\mathrm{Na}$ & СТC & & \\
\hline $\mathrm{S}_{1}$ & 3,45 & 6,78 & 6,9 & & 0,058 & 26,3 & 25,6 & 45 & & 36 & 7,8 \\
\hline $\mathrm{S}_{2}$ & 2,38 & 4,11 & 8,1 & 85 & 6,89 & 68,9 & 16,6 & 16 & 125,9 & 13 & 15,55 \\
\hline $\mathrm{S}_{3}$ & 4,76 & 8,21 & 7,6 & 191 & 3,50 & 14,2 & 17,6 & 6 & 62,0 & 11 & 2,18 \\
\hline $\mathrm{S}_{4}$ & 4,65 & 8,01 & 6,3 & 123 & 15,96 & 38,1 & 22,7 & 16 & 114,3 & 14 & 7,45 \\
\hline
\end{tabular}

S1 - Areia + Arisco + Composto 1:1:1, S2 - Areia + Arisco + Biofertilizante de caranguejo, S3 - Biofertilizante bovino aeróbio, S4 - Biofertilizante bovino anaeróbio; MO - Matéria orgânica. CTC = capacidade de troca de cátions; PST = porcentagem de sódio trocável; $\mathrm{Ce}=$ condutividade elétrica.

Fonte: Laboratório de Análise de Solos da UFC.

Na preparação da água salina foram utilizados os sais de $\mathrm{NaCl}, \mathrm{CaCl}_{2} \cdot 2 \mathrm{H}_{2} \mathrm{O}$ e $\mathrm{MgCl}_{2} \cdot 6 \mathrm{H}_{2} \mathrm{O}$, na proporção de 7:2:1(MEDEIROS, 1992). A irrigação com as fontes de água de diferentes salinidades 
foi iniciada após o desbaste e a quantidade de água aplicada diariamente às plantas foi calculada de acordo com o princípio do lisímetro de drenagem (BERNARDO et al., 2008), mantendo-se o solo na capacidade de campo.

Aos 50 dias após a semeadura, foram analisadas as seguintes variáveis: número de folhas, diâmetro do caule, altura de plantas e área foliar. 0 diâmetro do caule foi medido utilizando um paquímetro digital, a altura das plantas foi medida utilizando uma régua milimetrada e a área foliar foi determinada utilizando um medidor de área foliar ( $\mathrm{LI}$ - 3100, Area Meter, Li - Cor, In. Lincoln, Nebraska, USA), colocando-se a parte aérea no medidor para realização da leitura. Em seguida, as plantas foram coletadas e separadas em folhas + caules e raiz e colocadas em sacos de papel para secar em estufa de circulação forçada de ar a $60{ }^{\circ} \mathrm{C}$ para determinação da matéria seca da parte aérea, matéria seca da raiz e matéria seca total.

Os resultados foram submetidos à análise de variância e as médias comparadas pelo teste de Tukey com $\mathrm{p}<0,05$, utilizando o programa SAEG/UFV (RIBEIRO JÚNIOR, 2001).

\section{Resultados e discussão}

A análise de variância apresentada na Tabela 3 mostrou que os diferentes substratos influenciaram o número de folhas (NF), diâmetro caule (DC), matéria seca da parte aérea (MSPA), matéria seca da raiz (MSR) e matéria seca total (MST). As demais variáveis não foram influenciadas pelas águas de irrigação em nível de significância de 1 e 5 \% pelo teste F. Para a interação entre os substratos e a salinidade da água de irrigação, verificou-se que houve efeito significativo na altura de plantas (AP) e na área foliar (AF).

Tabela 3. Resumo da análise de variância, número de folhas (NF), diâmetro caulinar (DC), altura da planta $(A P)$, área foliar (AF), matéria seca da parte aérea (MSPA), matéria seca da raiz (MSR) e matéria seca total (MST) em plantas de girassol em função de diferentes substratos e salinidade da água de irrigação

\begin{tabular}{|c|c|c|c|c|c|c|c|c|}
\hline \multirow[t]{2}{*}{ FV } & \multirow[t]{2}{*}{ GL } & \multicolumn{7}{|c|}{ Quadrado médio } \\
\hline & & NF & DC & AP & AF & MSPA & MSR & MST \\
\hline Tratamentos & 9 & $22,35^{* *}$ & 4,93 ** & $3,34 * *$ & 311,3 ** & $12,63^{* *}$ & $0,93 * *$ & $17,8^{* *}$ \\
\hline Substrato (Ss) & 4 & $39,05^{* *}$ & $7,4^{* *}$ & $230,8 * *$ & $367,6 * *$ & $23,34 * *$ & $1,3 * *$ & $35^{* *}$ \\
\hline Salinidade (S) & 1 & $3,92 \mathrm{~ns}$ & $0,1 \mathrm{~ns}$ & $9,68 \mathrm{~ns}$ & $4,54 \mathrm{~ns}$ & $1,92 \mathrm{~ns}$ & $0,08 \mathrm{~ns}$ & $0,06 n s$ \\
\hline Ss $\times \mathrm{S}$ & 4 & $10,27 \mathrm{~ns}$ & $6,38 \mathrm{~ns}$ & $26,13^{*}$ & 333,1 ** & $4,59 n s$ & $0,09 n s$ & $4,93 \mathrm{~ns}$ \\
\hline Resíduo & 30 & 3,72 & 1,24 & 34,5 & 39,88 & 2,09 & 0,16 & 2,6 \\
\hline Total & 39 & - & - & & - & - & & \\
\hline CV (\%) & & 19,68 & 16,28 & 15,48 & 18,75 & 33,48 & 22,8 & 21,4 \\
\hline
\end{tabular}

Na Tabela 4, pode-se verificar a avaliação dos valores médios do número de folhas, diâmetro do caule e altura das plantas de girassol cultivadas em diferentes substratos. 
Tabela 4. Teste de comparação de médias do número de folhas, diâmetro do caule e altura de plantas de girassol submetidas a diferentes substratos.

Substratos

\begin{tabular}{ccc}
\hline $\mathrm{S}_{1}$ & $8,0 \mathrm{~b}$ & $4,23 \mathrm{~b}$ \\
$\mathrm{~S}_{2}$ & $10,7 \mathrm{a}$ & $3,96 \mathrm{~b}$ \\
$\mathrm{~S}_{3}$ & $9,9 \mathrm{a}$ & $6,36 \mathrm{a}$ \\
$\mathrm{S}_{4}$ & $4,8 \mathrm{c}$ & $7,57 \mathrm{a}$ \\
\hline $\mathrm{MG}$ & 8,35 & 5,53 \\
\hline $\mathrm{CV}(\%)$ & 15,96 & 21,16 \\
\hline
\end{tabular}

S1 = areia + arisco + composto orgânico; S2 = areia + arisco + biofertilizante de caranguejo; S3 = areia + arisco + biofertilizante bovino de fermentação aeróbia; S4 = areia + arisco + biofertilizante bovino de fermentação anaeróbia; Médias seguidas da mesma letra na coluna não diferem estatisticamente entre si pelo teste de Tukey a $5 \%$ de probabilidade estatística; CV = coeficiente de variação; $M G=$ média geral.

Fonte: Elaborada pelos autores.

Com relação aos valores médios do número de folhas, verificou-se que houve diferença significativa do número de folhas das plantas de girassol avaliadas, sendo que as plantas cultivadas nos substratos $\mathrm{S}_{2}$ e $\mathrm{S}_{3}$ apresentaram o maior número de folhas por planta, e as plantas cultivadas com $\mathrm{S}_{4}$ apresentaram os menores valores de número de folhas por planta, sendo essa redução de 55,1\% quando comparada com os valores do número de folhas das plantas adubadas com biofertilizante de caranguejo.

Andrade et al. (2012), ao estudar o crescimento de girassóis ornamentais em sistema de produção orgânico e irrigado com água residuária tratada, verificaram um aumento no número de folhas das plantas irrigadas com água residuária de esgoto doméstico tratado em relação ao tratamento irrigado com água de abastecimento. Avaliando o crescimento de plantas de girassol em função da salinidade da água de irrigação e da adubação nitrogenada, Guedes Filho et al. (2013) verificaram que, com o aumento da salinidade da água de irrigação, houve redução no número de folhas das plantas avaliadas, sendo que ao aumentar as doses de nitrogênio houve estimulação da emissão foliar.

No teste de comparação de médias do diâmetro do caule de plantas de girassol (Tabela 3), verifica-se que houve diferença estatística entre as plantas avaliadas, sendo que as plantas cultivadas nos tratamentos $S_{1}$ e $S_{2}$ não diferiram estatisticamente entre si. Da mesma forma, as plantas cultivadas nos tratamentos $\mathrm{S}_{3}$ e $\mathrm{S}_{4}$ também não diferiram estatisticamente entre si. Os maiores valores de diâmetro do caule foram observados nos tratamentos $S_{3}$ e $S_{4}$.

Sousa et al. (2012b), avaliando o desenvolvimento de plantas de milho sob diferentes doses de biofertilizante bovino com diferentes condutividades elétricas da água de irrigação, verificaram que quanto maior a dose do biofertilizante aplicado, maiores foram os valores do diâmetro do caule das plantas de milho estudadas. Esses autores verificaram ainda que na presença do biofertilizante bovino de fermentação anaeróbia os valores de altura de plantas apresentaram melhor desempenho quando essas foram submetidas a uma menor condutividade elétrica da água de irrigação.

$\mathrm{Na}$ Tabela 5 pode-se verificar que houve diferença significativa entre as médias das alturas de plantas e área foliar de plantas de girassol irrigadas com águas de baixa e alta salinidade cultivadas em diferentes substratos. 
Tabela 5. Teste de comparação de médias para a área foliar da cultura do girassol submetido a diferentes substratos.

\begin{tabular}{ccccc}
\hline \multirow{2}{*}{ Substratos } & \multicolumn{4}{c}{ Altura de plantas } \\
& \multicolumn{4}{c}{ Água de irrigação } \\
\cline { 2 - 5 } & 0,8 & 5 & 0,8 & 5 \\
\cline { 2 - 5 } $\mathrm{S}_{1}$ & $8,64 \mathrm{Ba}$ & $6,12 \mathrm{Bb}$ & $32,02 \mathrm{Ab}$ & $40,67 \mathrm{Ab}$ \\
$\mathrm{S}_{2}$ & $19,44 \mathrm{Aa}$ & $15,56 \mathrm{Ab}$ & $105,51 \mathrm{Aa}$ & $94,42 \mathrm{Ba}$ \\
$\mathrm{S}_{3}$ & $10,6 \mathrm{Ba}$ & $7,6 \mathrm{Bb}$ & $36,99 \mathrm{Ab}$ & $31,24 \mathrm{Bb}$ \\
$\mathrm{S}_{4}$ & $17,64 \mathrm{Aa}$ & $12,7 \mathrm{Ab}$ & $102,37 \mathrm{Aa}$ & $67,54 \mathrm{Ba}$ \\
\hline $\mathrm{MG}$ & 8,35 & 13,41 & 69,22 & 58,46 \\
\hline $\mathrm{CV}$ & 15,96 & 26,55 & 18,55 & 24,12 \\
\hline
\end{tabular}

$\mathrm{S}_{1}=$ areia + arisco + composto orgânico; $\mathrm{S}_{2}=$ areia + arisco + biofertilizante de caranguejo; $\mathrm{S}_{3}=$ areia + arisco + biofertilizante bovino de fermentação aeróbia; $\mathrm{S}_{4}=$ areia + arisco + biofertilizante bovino de fermentação anaeróbia; Médias seguidas da mesma letra não diferem estatisticamente entre si pelo teste de Tukey a $5 \%$ de probabilidade estatística; CV = coeficiente de variação; MG = média geral.

Fonte: Elaborada pelos autores.

Para os valores médios para a altura de plantas cultivadas sobre os diferentes substratos não houve diferença estatística. Porém, houve diferença entre as águas de irrigação, as plantas irrigadas

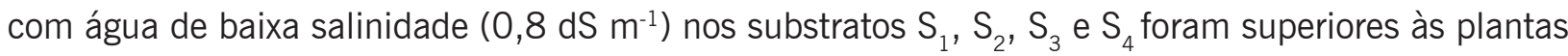
irrigadas com água de alta salinidade $\left(5,0 \mathrm{dS} \mathrm{m}^{-1}\right)$.

Souto et al. (2013) também verificaram que as plantas irrigadas com água de baixa salinidade na presença do biofertilizante bovino de fermentação anaeróbia apresentaram os maiores valores de altura de plantas em comparação aos demais tratamentos aplicados. Similarmente, Sousa et al. (2014), irrigando plantas de feijão-de-corda com água salina em solo com biofertilizante de caranguejo, constataram que esse insumo orgânico atenuou o estresse salino sobre a altura das plantas.

Com relação à área foliar das plantas de girassol avaliadas, observa-se que não houve diferença estatística para as plantas cultivadas no substrato $S_{1}$ na água de baixa e alta salinidade, enquanto nos tratamentos $\mathrm{S}_{2}, \mathrm{~S}_{3}$ e $\mathrm{S}_{4}$ houve diferença estatística para área foliar de plantas de girassol irrigadas com água de baixa e alta salinidade (tabela 4 ).

Em condições de adubação orgânica, utilizando biofertilizante bovino, Lima et al. (2013) também verificaram um melhor desempenho das plantas de gergelim avaliadas. Adicionalmente, Travassos et al. (2011), avaliando plantas de girassol irrigadas com águas de diferentes condutividades, verificaram que a área foliar decresceu linearmente com o aumento da salinidade da água de irrigação.

Na Tabela 6, têm-se os valores médios de matéria seca da parte aérea, matéria seca da raiz e matéria seca total das plantas de girassol avaliadas durante o experimento. A partir das médias avaliadas, pode-se verificar que houve diferença significativa nos valores de matéria seca da parte aérea do girassol estudado, sendo que as plantas cultivadas nos substratos $\mathrm{S}_{3}$ e $\mathrm{S}_{4}$ obtiveram os maiores valores entre todos os substratos estudados e não diferiram estatisticamente entre si. 
Tabela 6. Valores médios de matéria seca da matéria seca da parte área (MSPA) da raiz (MSR) e matéria seca total (MST) de plantas de girassol em diferentes substratos.

\begin{tabular}{|c|c|c|c|}
\hline Substratos & MSPA & MSR & MST \\
\hline $\mathrm{S}_{1}$ & $0,92 b$ & $0,24 b$ & $0,99 b$ \\
\hline $\mathrm{S}_{2}$ & $1,02 b$ & $0,22 b$ & $1,03 b$ \\
\hline $\mathrm{S}_{3}$ & $3,36 a$ & $1,21 \mathrm{a}$ & $4,6 a$ \\
\hline $\mathrm{S}_{4}$ & $2,78 a$ & $1,29 a$ & $4,69 a$ \\
\hline$M G$ & 2,02 & 0,74 & 2,82 \\
\hline CV (\%) & 28,7 & 25,8 & 32,54 \\
\hline
\end{tabular}

Cavalcante et al. (2010), estudando o crescimento inicial de mudas de plantas de goiabeira em solo salino, também verificaram aumento da produção da biomassa seca da parte aérea em função do aumento das doses de esterco bovino líquido aplicado. Similarmente, Costa et al. (2014) verificaram maior matéria seca da parte aérea em plantas de amendoim cultivadas em substrato contendo biofertilizante bovino. Esses resultados ainda estão compatíveis com os dados obtidos por Lima et al. (2012) ao constatarem aumento da matéria seca da parte aérea de plantas de milho adubadas com biofertilizante bovino.

Em relação à matéria seca da raiz, também foi verificado que houve diferença estatística entre os tratamentos aplicados, e os substratos $\mathrm{S}_{3}$ e $\mathrm{S}_{4}$ apresentaram os maiores valores em relação aos demais. Resultado semelhante foi observado por Sousa et al. (2014), que estudaram a cultura do feijão-de-corda em solo com biofertilizante de caranguejo e bovino.

Com relação à matéria seca total nos diferentes substratos, também destacaram-se os biofertilizantes de fermentação aeróbia e anaeróbia (substratos $\mathrm{S}_{3}$ e $\mathrm{S}_{4}$, respectivamente), que apresentaram os maiores valores médios de matéria seca total, assim como Medeiros et al. (2011), que, estudando a cultura do tomate-cereja sob diferentes níveis de salinidade em diferentes substratos, afirmaram que os substratos com biofertilizantes apresentaram maiores valores médios de matéria seca total. Da mesma forma, Mesquita et al. (2010) concluíram que na presença do biofertilizante bovino, após 65 dias após a emergência de plantas de maracujazeiro amarelo, a MST foi significativamente superior quando comparada à ausência do insumo orgânico.

\section{Conclusões}

$\mathrm{O}_{3}$ e $\circ \mathrm{S}_{4}$ proporcionam maior altura de planta e área foliar nas plantas irrigadas com água de baixa salinidade.

As plantas cultivadas com o $\mathrm{S}_{3}$ e $\mathrm{S}_{4}$ apresentaram maiores valores em número de folhas, diâmetro do caule, matéria seca da parte aérea, da raiz e total. 


\title{
Agronomic characteristics of sunflower crop irrigated with saline waters in substrates with organic fertilizers
}

\begin{abstract}
Plants respond differently to the effects of salts in the distinct phases of their cycle. However, the use of organic conditioners may mitigate the effect of salinity on the growth of plants. This study aimed to evaluate the effect of salt stress on the growth of sunflower plants in soil with organic fertilizers. The study was conducted in the experimental area of Estação Agrometeorológica, UFC, Fortaleza, in the period of September-November 2013. The experimental design was completely randomized in a $4 \times 2$ factorial design, referring to the organic fertilizers applied to the substrate at one time (S1 = thick sand + sand + organic compound; S2 = sand + thick sand + crab biofertilizer; S3 $=$ sand + thick sand + bovine biofertilizer aerobic fermentation; S4 $=$ sand + thick sand + bovine biofertilizer anaerobic fermentation), with two electrical conductivities of irrigation water $\left(0.8 \mathrm{dS} \mathrm{m}^{-1}\right.$

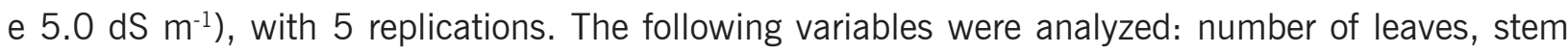
diameter, leaf area and plant height, shoot, root and total dry matter. The S3 and S4 provide greater plant height and leaf area in plants irrigated with low salinity water. Plants grown with the S3 and S4 showed higher values of leaves, stem diameter, dry matter of shoot, root and total.
\end{abstract}

Keywords: Helianthus annuus. L. Salt stress. Organic conditioners.

\section{Referências}

ANDRADE, L. O.; GHEYI, H. H.; NOBRE, R. G.; DIAS, N. S.; NASCIMENTO, E. C. S. Crescimento de girassóis ornamental em sistema de produção orgânica e irrigada com água residuária tratada. Irriga, Edição Especial, p. 69 - 82, 2012

BERNARDO, S.; MANTOVANI, E. C.; SOARES, A. A. Manual de Irrigação. Viçosa: UFV, 2008. 611 p. CASTRO, C.; FARIAS, J. R. B. Ecofisiologia do girassol. In: LEITE, R. M. V. B. C.; BRIGHENTI, A. M.; CASTRO, C. Girassol no Brasil. Londrina: 2005. p.164-218.

CAVALCANTE, L. F.; VIEIRA, M. S.; SANTOS, A. F. dos; OlIVEIRA, W. M.; NASCIMENTO, J. A. M. Água salina e esterco bovino líquido na formação de mudas de goiabeira cultivar paluma. Revista Brasileira de Fruticultura, v. 32, n. 1, p. 251-261, 2010.

COSTA, F. R. B.; GOMES, K. R.; SOUSA, G. G.; AZEVEDO, B. M.; MONTEIRO, F. J. F.; VIANA, T. V. A. Crescimento inicial do amendoinzeiro irrigado com águas salinas em diferentes substratos, Revista Brasileira de Agricultura Irrigada, v. 8, n. 6, p. 466 - 475, 2014.

EMPRESA BRASILEIRA DE PESQUISA AGROPECUÁRIA (EMBRAPA). Colheita do girassol. Londrina: Empresa Brasileira de Pesquisa Agropecuária-CNPSo, 1997. 25p. (Documentos, 92).

GOMES, K. R.; AMORIM, A. V.; FERREIRA, F. J.; ANDRADE FILHO, F. L.; LACERDA, C. F.; GOMES FILHO, E. Respostas de crescimento e fisiologia do milho submetido a estresse salino com diferentes espaçamentos de cultivo. Revista Brasileira de Engenharia Agrícola e Ambiental, v. 15, p. 365-370, 2011. 
GUEDES FILHO, D. H.; SANTOS, J. B.; GHEYI, H. R.; CAVALCANTE, L. F.; FARIAS, H. L. Biometria do girassol em função da salinidade da água de irrigação e da adubação nitrogenada. Revista Brasileira de Agricultura Irrigada, v. 7, n. 5, p. 277 - 289, 2013.

KÖPPEN, W. Climatologia: con un estudio de los climas de la tierra. Mexico: Fondo de Cultura Economica, 1918. 478p.

LACERDA, C. F.; SOUSA, G. G.; SILVA, F. L. B.; GUIMARÃES, F. V. A.; SILVA, G. L.; CAVALCANTE, L. F. Soilsalinization and maize and cowpea yield in the croprotation system using saline waters. Engenharia Agrícola, v. 31, n. 4, p. 663-675, 2011.

LEITE, R. M. V. B. C.; CASTRO, C.; BRIGHERTI, A. M.; OLIVEIRA, F. A.; CARVALHO, C. G. P.; OLIVEIRA, A. C. B. Indicações para o cultivo de girassol nos Estados do Rio Grande do Sul, Paraná, Mato Grosso do Sul, Mato Grosso, Goiás e Roraima. Londrina: Embrapa, 2007. 4p.

LIMA, F. A.; SOUSA, G. G.; VIANA, T. V. A.; PINHEIRO NETO, L. G.; AZEVEDO, B. M.; CARVALHO, C. M. Irrigação da cultura do gergelim em solo com biofertilizante bovino. Revista Brasileira de Agricultura Irrigada, v. 7, n. 2, p. $102-111,2013$.

LIMA, J. G. A.; VIANA, T. V. A.; SOUSA, G. G.; WANDERLEY, J. A. C.; PINHEIRO NETO, L. G.; AZEVEDO, B. M. Crescimento inicial do milho fertirrigado com biofertilizante. Revista Agropecuária Científica no Semiárido, v. 8, n. 1, p. 39- 44, 2012.

MEDEIROS, R. F.; CAVALCANTE, L. F.; MESQUITA, F. O.; RODRIGUES, R. M.; SOUSA, G. G.; DINIZ, A. A. Crescimento inicial do tomateiro-cereja sob irrigação com águas salinas em solo com biofertilizantes bovinos. Revista Brasileira de Engenharia Agrícola e Ambiental, v. 15, n. 5, p. 505 - 511 , 2011.

MEDEIROS, J. F. Qualidade da água de irrigação utilizada nas propriedades assistidas pelo "GAT" nos Estados do RN, PB, CE e avaliação da salinidade dos solos. 1992. 173 f. Dissertação (Mestrado em Engenharia Agrícola) - Universidade Federal da Paraíba, Campina Grande.

MESquitA, F. O.; CAVAlCANTE, L. F.; REBEQUI, A. M.; LIMA NETO, A. J.; NUNES, J. C.; NASCIMENTO, J. A. M. Produção de mudas de maracujazeiro amarelo em substrato com biofertilizante bovino irrigado com águas salinas. Revista Agropecuária Técnica, v. 31, n. 2, p. 134-142, 2010.

NEVES, A. L. R.; LACERDA, C. F.; GUIMARÃES, F. V. A.; HERNANDEZ, F. F. F.; SILVA, F. B.; PRISCO, J. T.; GHEYI, H. R. Acumulação de biomassa e extração de nutrientes por plantas de feijão-de-corda irrigadas com água salina em diferentes estádios de desenvolvimento. Revista Ciência Rural, v. 39, n. 3, p.758-765, 2009.

PENTEADO, S. R. Adubação Orgânica: Compostos orgânicos e biofertilizantes. 2. ed. Campinas: Edição do autor, 2007.162 p.

PRAZERES, S. S.; LACERDA, C. F.; BARBOSA, F. E. L.; AMORIM, A. V.; ARAUJO, I. C. S.; Cavalcante, L. F. Crescimento e trocas gasosas de plantas de feijão-caupi sob irrigação salina e doses de potássio. Revista Agro@mbiente On-line, v. 9, n. 2, p. 111-118, 2015.

RIBEIRO JÚNIOR, J. I. Análises estatísticas no SAEG. Viçosa: UFV, 2001. 301 p. 
SANTANA, M. J.; ASSUNÇÃO, J.; SOUZA, K. J.; SOUSA, A. M. G.; VASCONCELOS, C. L.; BASTOS, L. A. Efeitos da salinidade da água de irrigação na brotação e desenvolvimento inicial da cana-de-açúcar (saccharumspp) e em solos com diferentes níveis texturais. Revista Ciência e Agrotecnologia, v. 31, n. 5, p.1470-1476, 2007.

SANTOS, A. P. G.; VIANA, T. V. A.; SOUSA, G. G.; GOMES-DO-Ó, L. M.; AZEVEDO, B. M.; SANTOS, A. M. Produtividade e qualidade de frutos do meloeiro em função de tipos e doses de biofertilizantes. Revista Horticultura Brasileira, v. 32, n. 4, p. 409-416, 2014.

SILVA, F. L. B.; LACERDA, C. F.; SOUSA, G. G.; NEVES, A. L. R.; SILVA, G. L.; SOUSA, C. H. C. Interação entre salinidade e biofertilizante bovino na cultura do feijão-de-corda. Revista Brasileira de Engenharia Agrícola e Ambiental, v. 15, n. 4, p.383-389, 2011.

SILVA, F. L. B. da; LACERDA, C. F. de; NEVES; A. L. R.;SOUSA, G. G. de; SOUSA, C. H. C. de; FERREIRA, F. J. Irrigação com águas salinas e uso de biofertilizante bovino nas trocas gasosas e produtividade de feijão-de-corda. Irriga, v. 18, n. 2, p. 304-317, 2013.

SousA, G. G.; AZEVedo, B. M.; AlBuquerque, A. H. P.; MesquitA, J. B. R.; ViANA, T. V. A. Características agronômicas do amendoinzeiro sob irrigação com águas salinas em solo com biofertilizantes. Revista Agroambiente, v. 6, n. 2, p. 124-132, maio/ago, 2012a.

SOUSA, G. G.; MARINHO, A. B.; AlBUqueRquE, A. H. P.; VIANA, T. V. A.; AZEVEDO, B. M. Crescimento inicial do milho sob diferentes concentrações de biofertilizante bovino irrigado com águas salinas. Revista Ciência Agronômica, Fortaleza, CE, CCA/UFC, v. 43, n. 2, p. 237-245, 2012b.

SOUSA, G. G.; VIANA, T. V. A.; LACERDA, C. F.; AZEVEDO, B. M.; SILVA, G. L.; COSTA, F. R. B. Estresse salino em plantas de feijão-caupi em solo com fertilizantes orgânicos. Revista Agro@mbiente, v. 8 , n. 3, p. 359-367, 2014.

SOUTO, A. G. L.; CAVAlCANTE, L. F.; NASCiMentO, J. A. M.; MESQUitA, F. O.; LiMA NETO, A. J. Comportamento do noni à salinidade da água de irrigação em solo com biofertilizante bovino. Irriga, v. 18 , n. 3, p. 442-453, 2013.

TRAVASSOS, K. D.; SOARES, F. A. L.; GHEYI, H. R.; DIAS, N. S.; NOBRE, R. G. Crescimento e produção de flores de girassol irrigado com água salobra. Revista Brasileira de Agricultura Irrigada, v. 5, n. 2, p. 123-133, 2011.

UNGARO, M. R. G. Potencial da cultura do girassol como fonte de matéria-prima para o programa nacional de produção e uso de biodiesel. In: CAMARA, G. M.; HEIFFIG, L. S. (ed.) Agronegócio de plantas oleaginosas: matérias-primas para o biodiesel. Piracicaba: ESALQ, 2006. p. 57-80.

ZOBIOLE, L. H. S.; CASTRO, C. de; OLIVEIRA, F. A. de; OLIVEIRA JUNIOR, A. de. Marcha de absorção de macronutrientes na cultura do girassol. Revista Brasileira de Ciência do Solo, v. 34, n. 2, p. 425-434, 2010.

\section{Histórico editorial:}

Submetido em: 06/11/2015

Aceito em: 03/03/2016 
Como citar:

$\underline{A B N T}$

SOUSA, G. G. de; VIANA, T. V. A.; REBOUÇAS NETO, M. O.; SILVA, G. L. da; AZEVEDO, B. M. de; COSTA, F. R. B. Características agronômicas do girassol irrigado com águas salinas em substratos com fertilizantes orgânicos. Revista Agrogeoambiental, Pouso Alegre, v. 9, n. 1, p.65-75, jan./mar. 2017. DOI: http://dx.doi.org/10.18406/2316-1817v9n12017920

APA

SOUSA, G. G. de, VIANA, T. V. A., REBOUÇAS NETO, M. O., SILVA, G. L. da, AZEVEDO, B. M. de \& COSTA, F. R. B. (2017).Características agronômicas do girassol irrigado com águas salinas em substratos com fertilizantes orgânicos. Revista Agrogeoambiental, 9 (1), 65-75. DOI: http://dx.doi.org/10.18406/2316-1817v9n12017920

$\underline{\text { ISO }}$

SOUSA, G. G. de; VIANA, T. V. A.; REBOUÇAS NETO, M. O.; SILVA, G. L. da; AZEVEDO, B. M. de e COSTA, F. R. B. Características agronômicas do girassol irrigado com águas salinas em substratos com fertilizantes orgânicos. Revista Agrogeoambiental. 2017, vol. 9, n. 1, pp. 65-75. elSSN 2316-1817. DOI: http://dx.doi.org/10.18406/2316-1817v9n12017920

\section{VANCOUVER}

Sousa GG, Viana TVA, Rebouças Neto MO, Silva GL, Azevedo BM, Costa FRB. Características agronômicas do girassol irrigado com águas salinas em substratos com fertilizantes orgânicos. Rev agrogeoambiental. 2017 jan/mar; 9(1): 65-75. DOI: http://dx.doi.org/10.18406/2316-1817v9n12017920 